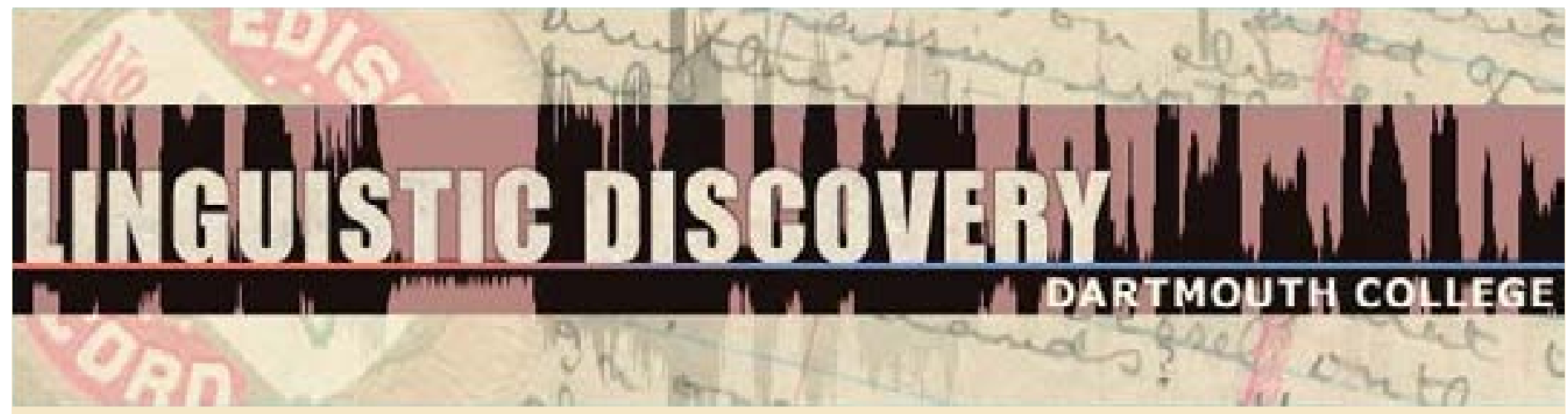

\begin{tabular}{|l|}
\hline Volume 12 \\
Issue 2 \\
2014 \\
\hline
\end{tabular}

\title{
Cross-Linguistic Variation in the Treatment of Beneficiaries and the Argument vs. Adjunct Distinction
}

Denis Creissels

Université Lumière (Lyon 2)

doi: 10.1349/PS1.1537-0852.A.445

url: http://journals.dartmouth.edu/cgi-bin/WebObjects/ Journals.woa/1/xmlpage/1/article/445 


\section{Cross-Linguistic Variation in the Treatment of Beneficiaries and the Argument vs. Adjunct Distinction \\ Denis Creissels}

Université Lumière (Lyon 2)

This paper compares the expression of beneficiaries with that of typical arguments and typical adjuncts in a sample of languages illustrating the variation in the extent to which NPs encoding beneficiaries show a syntactic behavior more or less similar to that of typical arguments or typical adjuncts. The observations support the position according to which semantic argumenthood as a comparative concept must be distinguished from its possible syntactic correlates, and must be defined as a scalar rather than categorical concept reflecting the interaction between the various factors that may contribute to defining the degree of involvement of participants in an event.

\section{Introduction}

This paper argues against the idea of a straightforward relationship between semantic argumenthood and its possible morphosyntactic correlates, and in favor of the position according to which:

- argumenthood should be defined in semantic terms as a comparative concept independent from its possible correlates in the syntactic organization of individual languages,

- semantic argumenthood should be defined as a scalar rather than categorical concept, and the definition should be formulated in such a way as to assign the highest degree of argumenthood to participants showing the highest possible degree of involvement in an event, and the lowest degree of argumenthood to phrases that do not refer to participants in the event denoted by the verb, but to its circumstances.

In this paper, I do not propose a precise definition of the features that might be relevant to a definition of semantic argumenthood compatible with the cross-linguistic variation observed in the syntactic contrasts between NPs commonly considered as expressing arguments or adjuncts, and I do not discuss the criteria for distinguishing arguments from adjuncts either. The notion of argumenthood has been discussed, and argumenthood tests have been proposed, in classical works such as Jackendoff (1977), Marantz (1984), Pollard and Sag (1987), Grimshaw (1990). Schütze (1995) provides both a detailed survey and an interesting discussion in which he argues in favor of a scalar conception of argumenthood. However, the detailed discussions of argumenthood one can find in the literature almost always deal exclusively with English, which leaves open the question of the cross-linguistic relevance of their conclusions. In this paper, I would like to propose another possible approach to argumenthood as a comparative concept and its syntactic correlates, based on the observation of cross-linguistic variations in the extent to which NPs to which a particular semantic role is assigned show a syntactic behavior more or less similar to that of typical arguments or typical adjuncts.

The role of beneficiary provides a particularly good illustration of the extent to which the behavior of NPs fulfilling a given semantic role may vary cross-linguistically in comparison with the behavior of typical arguments or typical adjuncts, providing thus clear support to the prototype approach to argumenthood. The status of beneficiaries as adjuncts is commonly 
considered relatively uncontroversial (Kittilä \& Zúñiga 2010: 4), but a cross-linguistic comparison of the expression of beneficiaries with that of typical arguments and typical adjuncts reveals that things are not so straightforward.

The paper is organized as follows. Section 2 consists of some general comments about the approach to the argument vs. adjunct distinction explored in this paper. Section 3 illustrates the case of beneficiaries encoded in the same way as typical adjuncts. Section 4 illustrates the case of beneficiaries encoded like typical arguments. Section 5 discusses the status of beneficiaries in applicative constructions. Section 6 discusses a parallelism between beneficiaries in languages with obligatory applicatives and agents in transitivizing languages. Section 7 puts forward some concluding remarks.

\section{A Prototype Approach to the Argument vs. Adjunct Distinction}

\subsection{Essential vs. non-essential participants and obligatory $v s$. optional noun phrases}

The basic intuition underlying the argument vs. adjunct distinction is that arguments are in some sense required by the verb, which 'governs' them or 'subcategorizes' for them. A common explanation of this intuition is that each verb encodes a particular kind of event whose definition requires the mention of a given number of essential participants.

Semantic argumenthood can therefore be defined in terms of degree of involvement of participants in the event. The notion of involvement of a participant in an event is a complex notion which I will not try to discuss in detail here, but it can safely be assumed that a typical argument is a participant without which the kind of event referred to by the verbal lexeme cannot be conceived. The crucial question is to what extent this is reflected in the syntactic properties of NPs representing such participants.

It is not difficult to find verbs with valency properties that contradict the idea of a straightforward correspondence between essential participants in a given type of event and NPs in the construction of the corresponding verb, and for which the discrepancy cannot be explained as the result of operations modifying a basic argument structure in which all essential participants are included.

A particularly clear case is that of the verbs of eating. The act of eating cannot be defined without mentioning two essential participants, but many languages have two translational equivalents of English eat, one of them bivalent and the other monovalent, that cannot be analyzed as related to each other through some valency operation, as illustrated by Akhvakh $\bar{q}$ 'am- (quoted in the infinitive as $\bar{q}$ 'onnua) 'eat (transitive)' vs. $\tilde{u} k$ - (quoted in the infinitive as ükunuьa) 'eat (intransitive) - Ex. (1)

(1) Northern Akhvakh (Nakh-Daghestanian, Russia - personal documentation)

a. RiL̄'i $\bar{q}$ 'ama!

meat eat.IMP

'Eat the meat!' 
b. Ĩč’i ũka!

first eat.IMP

'Eat first!'

c. *Rī̄'i ũka!

meat eat.IMP

'Eat the meat!' can only be expressed as (a)

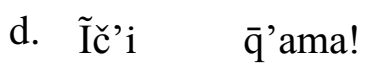

First eat.IMP

'Eat it/that first!' - this sentence cannot be used in the same meaning as (b), and is acceptable only if the unexpressed participant can be identified to a referent retrievable from the context or the situation.

What this example suggests is that, although being essential or obligatory for the meaning of the verb is unquestionably a crucial component of semantic argumenthood as a comparative concept, it is not necessarily reflected in the syntax straightforwardly, since some verbs do not allow the expression of an obligatory participant.

At the syntactic level, languages differ greatly in the way they regulate the obligatoriness $v s$. optionality of noun phrases. Crucially, as just illustrated by the example of intransitive 'eat' verbs, the obligatoriness of a given participant role with a given verb at the semantic level is not necessarily reflected by the non-omissibility of the corresponding noun phrase at the syntactic level. The only general difference between arguments and adjuncts with respect to obligatoriness $v s$. optionality is that adjuncts can only be optional, and lack of specification of the corresponding meaning is the only possible interpretation of the absence of a given type of adjunct, whereas cross-linguistically, unexpressed arguments have two possible types of interpretation: either they encode lack of specification of the corresponding participant, or they are identified to a referent retrievable from the context or the situation, as in Ex. (1d) above.

Consequently, the non-omissibility of a noun phrase, or the fact that the omission of a given noun phrase triggers an anaphoric interpretation, can constitute criteria for identiying it as an argument, but omissibility interpreted as lack of specification gives no clue as to whether the noun phrase in question must be viewed as an argument or an adjunct.

\subsection{Arguments $v s$. adjuncts and core syntactic terms vs. obliques}

Descriptions of individual languages classify the possible morphosyntactic behaviors of noun phrases involved in predicative constructions. The criteria commonly used include obligatoriness, linear order, flagging, indexation, and behavior in operations such as reflexivization, passivization, relativization, focalization, etc.

It is generally easy to identify some of the types of morphosyntactic behavior identified in a language as typically selected for noun phrases representing participants whose semantic role forms part of the lexical meaning of the verb, at least in clauses whose construction does not involve operations on the basic argument structure of the head verb. Noun phrases showing a morphosyntactic behavior of this kind are commonly referred to as core syntactic terms, and 
noun phrases whose morphosyntactic behavior does not imply a relatively high position on the scale of argumenthood can be designated as obliques. The criteria distinguishing core NPs from oblique NPs are language-specific, and some criteria that are particularly useful is some languages or language families quite obviously do not lend themselves to any generalization (for example, the distinction found in Mande languages between core NPs obligatorily preceding the verb and oblique NPs obligatorily following the verb), but the following cross-linguistic tendencies can be observed:

typical properties of core NPS no overt flagging indexation TAM-governed coding properties

unrestricted accessibility to various syntactic operations typical properties of oblique NPs overt flagging no indexation coding properties independent of TAM variations

restricted accessibility to various syntactic operations

The problem is that, here again, the implication flows in only one direction. Once the contrast between core syntactic terms and obliques has been established, in a given language, on the basis of morphosyntactic criteria, the morphosyntactic status of core term implies argumenthood, but the morphosyntactic status of oblique does not imply adjuncthood, and no clear-cut distinction must be expected to exist between true adjuncts and oblique arguments (noun phrases relatively high on the scale of argumenthood but encoded like typical adjuncts) if the distinction between arguments and adjuncts itself is conceived as scalar:

\begin{tabular}{|l|ll|}
\hline \multicolumn{2}{|c|}{ arguments } & adjuncts \\
\hline core syntactic terms & obliques \\
\hline
\end{tabular}

For example, as mentioned above, Mande languages have a particularly clear-cut distinction between syntactic core terms and obliques. Syntactic core terms precede the verb and are obligatory, ${ }^{1}$ whereas obliques follow the verb and are optional. No predicative construction can include more than two core terms: the subject in intransitive predication, the subject and the object in transitive predication. In the construction of semantically trivalent verbs, one of the three arguments must necessarily be encoded as an optional postpositional phrase in post-verbal position, and its behavioral properties do not distinguish it from obliques representing adjuncts. For example, Mandinka has two equivalents of English 'give': with dii (which by itself implies nothing more than transfer), the gift (alias theme) is represented by the object NP, whereas with só (which implies that the recipient becomes the possessor of the gift) the object NP represents

\footnotetext{
${ }^{1}$ As discussed in detail in Creissels (To appear (a)) for Mandinka, constructions in which one of the two arguments of transitive verbs is not expressed do not contradict the obligatoriness of core syntactic terms. Mandinka has a morphologically marked distinction between transitive and intransitive predication, and the constructions in which one of the two arguments of transitive verbs is not expressed are formally intransitive. Consequently, they cannot be analyzed as transitive constructions with a null argument and must be analyzed as involving valency alternations.
} 
the recipient - Ex. (2). It can be argued that prototypical transitivity is relevant here, since the choice between coding the recipient like the patient of a core transitive verb or like a peripheral participant correlates with a greater or lesser degree of affectedness, but the mere contrast between essential and non-essential participants cannot explain the contrast.

(2) Mandinka (Mande, Senegal/Gambia/Guinea Bissau - personal documentation)

\begin{tabular}{|c|c|c|c|c|}
\hline $\begin{array}{ll}\text { a. } & \text { Kew-ó } \\
\text { man-DEF }\end{array}$ & $\begin{array}{l}\text { ye } \\
\text { CMP.POS }\end{array}$ & $\begin{array}{l}\text { kód-ôo } \\
\text { money-DEF }\end{array}$ & $\begin{array}{l}\text { díi } \\
\text { give }\end{array}$ & $\begin{array}{l}\text { mus-óo } \\
\text { woman-DEF }\end{array}$ \\
\hline
\end{tabular}

'The man gave money to the woman.'

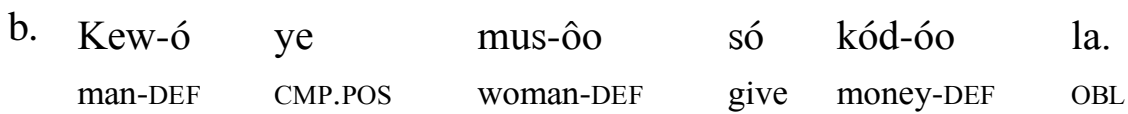

'The man gave money to the woman.'

At this point it is also interesting to mention the case of the Mandinka verb sáfée 'write'. Ex. (3a) illustrates the construction of this verb that can be considered as basic, with two core terms representing the two essential participants of the writing event: the writer and the thing written. There is however an alternative construction in which the thing written (the letter) is encoded as an oblique, and the object represents the person to which the letter is sent. It can be argued that this construction is motivated by the fact that it gives more salience to the recipient, but here again, there is no straightforward correspondence between the status of participants as essential or not in the lexical meaning of the verb and the syntactic distinction between core terms and obliques.

(3) Mandinka (Mande, Senegal/Gambia/Guinea Bissau - personal documentation)

$\begin{array}{lllllll}\text { a. Kew-ó } & \text { ye } & \text { batáay-ôo } & \text { sáfée } & \text { (a } & \text { díy-o } & \text { ye). } \\ \text { man-DEF } & \text { CMP.POS } & \text { letter-DEF } & \text { write } & \text { 3SG } & \text { son-DEF } & \text { BEN }\end{array}$

'The man wrote a letter (to his son).'

b. Kew-ó ye a dín-o sáfée (batáay-óo la).

man-DEF CMP.POS 3SG Son-DEF write letter-DEF OBL

'The man wrote (a letter) to his son (lit. wrote his son with a letter).'

It has often been suggested that oblique arguments differ from adjuncts in that the flagging of oblique arguments is a lexical property of verbs, whereas the flagging of adjuncts directly reflects their semantic role and does not depend on the particular verb they accompany, but detailed investigations of the uses of case markers or adpositions show that the reality is much more complex. 


\subsection{Argumenthood as a complex notion}

The view adopted here is that the semantic distinction between arguments and adjuncts cannot be conceived as a dichotomy between essential and non-essential participants, and that the definition of semantic argumenthood must be formulated in such a way as to be compatible with the fact that, as illustrated in Section 2.1, essential participants (in the sense of participants which must be mentioned in the definition of the lexical meaning of the verb) are not necessarily included in the basic argument structure of non-derived verbs.

The degree of involvement of the participants in the event is unquestionably a crucial component of semantic argumenthood, but not all essential participants are involved to the same degree, and it seems reasonable to attribute the highest degree of involvement to participants that are created, destroyed of modified as the result of the event denoted by the verb, and the lowest degree to inanimate participants that undergo no change of state or manipulation. Conversely, the phrases encoding the spatial or temporal location of an event can be viewed as typical adjuncts, since they refer to circumstances of the event rather than to participants involved therein.

However, even essential participants with an intrinsically high degree of involvement can be backgrounded in the argument structure of individual verbs, as illustrated by Ex. (1) above.

On the other hand, non-essential participants may show a relatively high degree of involvement. This is the case of beneficiaries, in the sense that events implying beneficiaries are typically motivated by another participant's desire to act in favor of the beneficiary. This is also the case of instruments, since instruments facilitate the action of another participant. ${ }^{2}$ In this perspective, phrases representing beneficiaries or instruments are clearly less adjunct-like that phrases referring to the location of the event.

The rest of this article will be devoted to an examination of cross-linguistic variation in the encoding of beneficiaries that support this approach to the argument vs. adjunct distinction, but before moving on to that, it is interesting to examine an example of cross-linguistic variation in the encoding of instrumentals illustrating the ambiguous status of instrumentals with respect to the argument $v s$. adjunct distinction.

As a rule, in European languages, hitting verbs have a construction that suggests analyzing them as bivalent verbs with two arguments representing the two essential participants of hitting events, the hitter and the hittee, the thing used to hit being a peripheral participant encoded as an adjunct. However, in several Nakh-Daghestanian languages, as illustrated by Akhvakh - Ex. (4), the hittee is in the Locative case, typically used to encode the location of an event, whereas the thing used to hit is encoded like the patient of core transitive verbs. In other words, in those languages, the way ' $\mathrm{X}$ hits $\mathrm{Y}$ with $\mathrm{Z}$ ' is expressed suggests a conceptualization that can be rendered approximately in English as ' $\mathrm{X}$ applies $\mathrm{Z}$ on $\mathrm{Y}$ '.

\footnotetext{
${ }^{2}$ An interesting discussion of the status of instrumentals with respect to argumenthood can be found in Schütze (1995: 124-132). The author argues against the common view according to which instrumentals can straightforwardly be viewed as adjuncts, and shows that "...there are some syntactic tests and some semantic tests according to which instrumentals are arguments. There are also some syntactic tests that indicate the opposite, and there are equivocal semantic tests, but there are no semantic tests that favour modifier [i.e., adjunct] status."
} 
(4) Northern Akhvakh (Nakh-Daghestanian, Russia - personal documentation)

Wašo-de beko-ge č'uli $\overline{\mathrm{L}}^{\prime \text { w}}$ arari.
boy-ERG snake-LOC stick hit.cMP
'The boy hit the snake with a stick.'
lit. 'The boy applied the stick on the snake.'

Wašo-de beko-ge č'uli $\overline{\mathrm{L}}^{\prime}$ 'warari.

boy-ERG snake-LOC stick hit.CMP

'The boy hit the snake with a stick.'

lit. 'The boy applied the stick on the snake.'

This confirms that the notion of peripheral or optional participant must be used with caution in discussions about argumenthood, since a participant with the same semantic role of instrument may be treated in the same way as typical adjuncts in the basic argument structure of non-derived hitting verbs in some languages, whereas in other languages, it is treated like typical arguments.

\section{Adjunct-like Beneficiaries}

As already explained above, Mandinka has a particularly clear-cut distinction between core syntactic terms and obliques. Core syntactic terms are obligatory, they are not flagged, and they precede the verb, whereas obliques follow the verb, are optional, and are typically encoded as postposition phrases. Ex. (5) shows that, in Mandinka, beneficiaries behave in the same way as typical adjuncts with respect to this distinction.

(5) Mandinka (Mande, Senegal/Gambia/Guinea Bissau - personal documentation)

a. Mus-óo ka dookúw-o ké karambún-o to. woman-DEF INCMP work-DEF do school-DEF at

'The woman works at the school.'

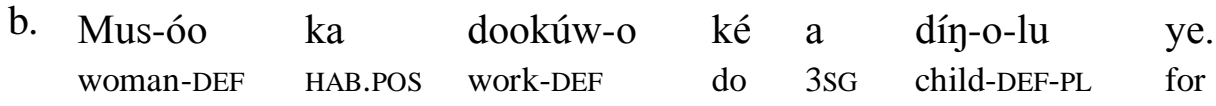

'The woman works for her children.'

Georgian provides another illustration of clearly adjunct-like beneficiaries. In Georgian, typical arguments are characterized by coding properties (case marking and indexation) that vary depending on the TAM value of the verb, whereas beneficiaries, like typical adjuncts, have invariable case marking and are not indexed on the verb - Ex. (6). 
(6) Georgian (Kartvelian, Georgia - Manana Topadze, personal communication)

a. C'erili davc'eret. letter we.wrote.it

'We wrote a letter.'

b. C'erili mogc'eret.

letter we.wrote.to.you

'We wrote you a letter.'

c. C'erili davc'eret šen-tvis.

letter we.wrote.it you-BeN

'We wrote a letter for you.'

d. C'eril-s davc'ert.

letter-DAT we.will.write.it

'We will write a letter.'

e. C'eril-s mogc'ert.

letter-DAT we.will.write.to.you

'We will write you a letter.'

f. C'eril-s davc'ert šen-tvis. letter-DAT we.wrote.it you-BEN

'We will write a letter for you.'

\section{Beneficiaries Encoded like Typical Arguments}

The English benefactive alternation - ex. (7) - shows that, in one and the same language, the same participant involved in the same event with the same role of beneficiary can be encoded like a typical adjunct or like the patient of monotransitive constructions, i.e., like a typical argument.

(7) English

a. Mary baked a cake for John.

b. Mary baked John a cake. 
A similar alternation is found in the Bantu language Eton - ex. (8). ${ }^{3}$

(8) Eton (Bantu, Cameroon - Van de Velde 2008: 306)

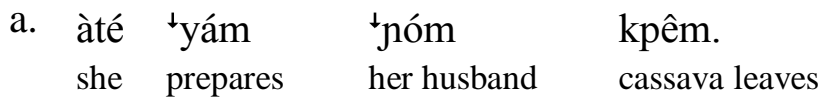

'She prepares cassava leaves for her husband.'

b. àté 'yám kpêm ású nóm.

she prepares cassava leaves for her husband

'She prepares cassava leaves for her husband.'

Of course, coding characteristics similar to those of the patient of monotransitive constructions do not ensure that the beneficiary in constructions of the type illustrated by Ex. (2b) and (3b) acquires all the syntactic properties typical of monotransitive patients, and there may be crosslinguistic variation on this point. It seems unquestionably universal, however, that the change in the coding properties of the beneficiary in the benefactive alternation cannot reasonably be viewed as reflecting a change in its semantic status.

\section{Beneficiaries and Applicatives}

\subsection{Beneficiaries and optional applicatives}

In typical applicative constructions, the verb is in a derived form, and the syntactic role typically assigned to monotransitive patients is assigned to a participant that could not fulfill this role with the non-derived form of the same verb. As discussed by Creissels (2004) and Peterson (2007: 4550), this definition leaves open two possibilities: either the same participant can be coded as an oblique term in the construction of the same verb in its non-applicative form (optional applicatives), or the use of the applicative form of the verb is the only way to code this participant as a term of the construction of the verb (obligatory applicatives).

In languages with optional applicatives, the situation is basically similar to the one in English or Eton, however with the difference that the alternation is morphologically oriented, and can therefore be viewed as a derivation converting a beneficiary encoded like typical adjuncts into a beneficiary encoded like typical arguments. In Ex. (9), the beneficiary in the construction of membeli 'buy' is encoded as a preposition phrase, whereas in the construction of the derived verb membelikan, it is represented by an unflagged noun phrase that follows the verb immediately, like the patient of typical transitive verbs.

(9) Indonesian (Malayo-Polynesian, Indonesia - Kaswanti 1997)

a. John membeli buku itu untuk Mary. John buy book that for Mary

'John bought that book for Mary.'

${ }^{3}$ In Bantu languages, beneficiaries are typically encoded as objects of applicative verbs - see Section 5.2, but contrary to most Bantu languages, Eton does not have an applicative derivational suffix. 
b. John membeli-kan Mary buku itu.
John buy-APPL
'John bought Mary that book.'

In some languages, the mismatch between semantic argumenthood and the coding properties of NPs in applicative constructions is even more marked, because the demotion of the initial object in the presence of an applied object is more marked than in the Indonesian example. For example, in Yup'ik, encoding the beneficiary in the construction of an applicative verb form like the patient argument of a typical transitive verb implies at the same time encoding the patient argument in the same way as typical adjuncts: in the basic transitive construction, the patient is represented by an absolutive noun phrase and is cross-referenced in the verb form, whereas in the applicative construction, it is encoded as a peripheral noun phrase in the 'ablative modalis' case - Ex. (10). Quite obviously, this change in the encoding of the patient cannot be considered as reflecting a modification of its status as an obligatory participant at semantic level.

(10) Yup'ik (Eskimo-Aleut, Alaska - Miyaoka 2012)

$\begin{array}{lll}\text { a. Arnam } & \text { neqet } & \text { keniraa. } \\ \text { woman.ERG.SG } & \text { fish.ABS.PL } & \text { cook.IND.3SG.3SG }\end{array}$

'The woman cooked the fish.'

b. Keniutaa neqmek angun.

cook.APPL.IND.3SG.3SG fish.ABM.SG man.ABS.SG

'She is cooking fish for the man.'

\subsection{Beneficiaries and obligatory applicatives}

Applicative constructions are commonly defined as involving a manipulation of argument structure by which participants otherwise encoded as adjuncts are assimilated to core arguments. However, this description does not account for languages in which some types of participant (in particular, beneficiaries) can only be encoded as objects of applicative verb forms.

For example, in Tswana, a language with a fully productive applicative derivation - Ex. (11), it is impossible to mention a beneficiary within a monoclausal construction headed by the verb apaya 'cook' in its non-derived form. Beneficiaries in Tswana can only be encoded as applied objects.

(11) Tswana (Bantu, Botswana and South Africa - personal documentation)

a. Mosadi o-apaya motogo.

CL1.woman CL1-cook CL3.porridge

'The woman is cooking porridge.'

b. Mosadi o-apeela bana motogo.

CL1.woman CL1-cook.APPL CL2.child CL3.porridge

'The woman is cooking porridge for the children.' 
In Tswana and other Bantu languages, beneficiaries are not fully assimilated to typical arguments, since the applicative marking on the verb can be viewed as an indication of their nonessential status. However, they are more argument-like than adjunct-like, since they have no possibility of being encoded in the same way as typical adjuncts. Moreover, with transitive verbs, their syntactic role is that of primary object in multiple object constructions. This means that the beneficiary NP is accessible to all the operations to which the patient NP is accessible in the single-object construction, for example passivization - Ex. (12).

(12) Tswana (Bantu, Botswana and South Africa - personal documentation)

$\begin{array}{lll}\text { Bana } & \text { ba-apeelwa } & \text { motogo. } \\ \text { CL2.child } & \text { CL2-cook.APPL.PASS } & \text { CL3.porridge }\end{array}$

'Porridge is being cooked for the children.'

lit. 'The children are being cooked-for porridge.'

In Tswana, beneficiary NPs encoded as applied objects have even priority over the other objects of the multiple object construction in some syntactic operations. For example, the beneficiary object licensed by applicative derivation can always be promoted to the role of subject of a passive verb form, whereas the presence of an object index representing the beneficiary blocks the promotion of the non-applied object to subject role - Ex. (13).

(13) Tswana (Bantu, Botswana and South Africa - personal documentation)

a. Ke-kwaletse bana buka.

1sG-write.APPL CL2.child CL9.book

'I wrote a book for children.'

b. Buka e e-kwaletswe bana.

CL9.book CL9.DEM CL9-write.APPL.PASS CL2.child

'This book was written for children.'

c. Bana ba-kwaletswe buka.

CL2.child CL2-write.APPL.PASS CL9.book

'A book was written for the children.'

lit. 'The children were written.for a book.'

d. *Buka e e-ba-kwaletswe.

CL9.book CL9.DEM CL9-CL2-write.APPL.PASS

intended: 'This book was written for them.'

e. Bana ba-e-kwaletswe.

CL2.child CL2-CL9-write.APPL.PASS

'It was written for the children.'

lit. 'The children were written.for it.' 
Among the languages in which beneficiaries are obligatorily encoded as objects in applicative constructions that do not have monoclausal non-applicative counterparts, the mismatch between the obligatoriness $v s$. optionality of participants at the semantic level and the syntactic status of NPs in applicative constructions may be more marked than in Bantu languages. For example, in Salish languages, the mere presence of a beneficiary NP implies that the obligatory participant encoded as the object if a beneficiary is not mentioned is demoted to oblique. In Salish languages, in the same way as in Tswana, beneficiaries can only be encoded as applied objects, but in addition to that, in the presence of an applied object, the obligatory participant encoded as the object of the non-applicative construction can only be encoded as an oblique with prepositional flagging - ex. (14).

(14) Shuswap (Salish, British Columbia - Kiyosawa \& Gerdts 2010: 3)

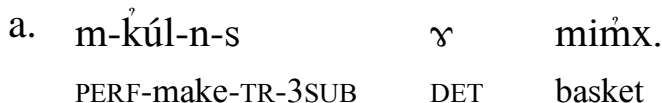

'She made the basket.'

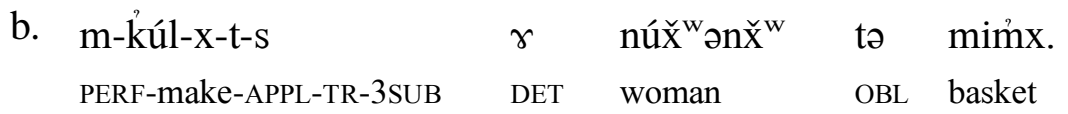

'She made a basket for the woman.'

\section{A Parallelism between Beneficiaries and Agents}

In this section, I would like to draw the attention to an interesting parallelism between the encoding of beneficiaries in languages in which beneficiaries are necessarily encoded as applied objects and the encoding of agents in transitivizing languages. It is commonly assumed that agents are typical arguments, whereas beneficiaries are typical adjuncts. In languages such as Georgian, as illustrated by Ex. (6) above, there is clear evidence that NPs encoding agents are core syntactic terms, whereas those encoding beneficiaries are obliques. But in some other languages, the encoding of agents involves phenomena quite similar to those involved in the encoding of beneficiaries in languages with obligatory applicatives. This contradicts the idea that there is a straightforward relationship between semantic role distinctions and the core vs. non-core distinction at syntactic level.

Transitivizing languages are defined by Nichols \& al. (2004) as languages in which transitive verbs tend to be derived from intransitive ones rather than the other way round. The agents of such verbs can only expressed within the frame of a valency-increasing derivation, like beneficiaries in languages with obligatory applicatives.

For example, in Akhvakh (Creissels, To appear (b)), the agent of 'break' can only be encoded as the ergative NP in the construction of the causative verb biq'ōruLa 'break (tr.)', derived from biq'urusa 'break (intr.)' - Ex. (15). 
(15) Northern Akhvakh (Nakh-Daghestanian, Russia - personal documentation)
a. İgo-L̄i
žari $\quad b-i q{ }^{\prime w}-\bar{e}$
godi.
window-GEN pane N.SG-break-CVB.N.SG
COP.N.SG

'The window pane broke.', NOT *'Someone broke the window pane.'

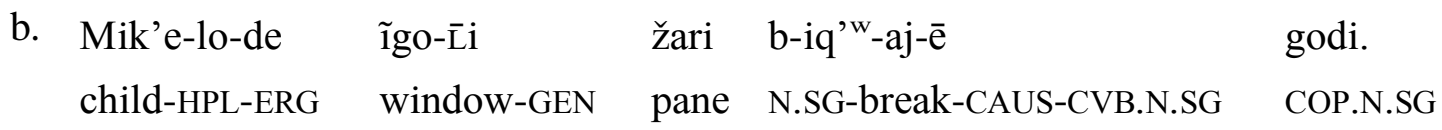

'The children have broken the window pane.'

The parallelism between agents in transitivizing languages and beneficiaries in languages with obligatory applicatives is not absolute, since even in very strongly transitivizing languages like Akhvakh, this treatment of agents is quite obviously conditioned by semantic factors. The possibility of conceiving the change of state triggered by the agent as a process that could as well develop more or less spontaneously, or without a straightforwardly identifiable causality chain, is certainly the reason why, even in very strongly transitivizing languages, NPs representing agents are also found with verbs that are not marked for causative derivation. For example, in Akhvakh, $\bar{q}$ 'inuruLa 'sew' is not derived from an intransitive verb, and it seems reasonable to think that this reflects the difficulty in conceiving the change of state undergone by the patient of 'sew' as a process that could develop spontaneously. In other words, the obligatoriness $v s$. optionality of participant roles is certainly crucial in this asymmetry between the treatment of agents in transitivizing languages and the treatment of beneficiaries in languages with obligatory applicatives.

It remains, however, that this parallelism between agents and beneficiaries in languages with two particular types of organization of verb valency is somewhat unexpected, and the questions raised by this parallelism should be discussed in any attempt to elaborate a general theory of the interface between semantic argumenthood and morphosyntax. Within the approach outlined in this paper, the explanation is that beneficiaries are not typical adjuncts, whereas the agents of verbs denoting changes of state that can develop more or less spontaneously do not show the highest possible degree of semantic argumenthood, since the process they trigger does not necessitate the participation of an agent

\section{Conclusion}

In this paper, I have tried to show that the morphosyntactic behavior of noun phrases representing beneficiaries shows considerable variation in its affinities, either with the behavior of noun phrases representing participants whose status as arguments is relatively uncontroversial, or with that of noun phrases representing typical adjuncts. Such a variation cannot reasonably be analyzed as reflecting differences in the semantic status of beneficiaries. In particular, it has nothing to do with the semantic obligatoriness or optionality of the participants in situations involving beneficiaries. The only possible conclusion is that the articulation between semantic argumenthood and differences in morphosyntactic behavior is less simple than commonly assumed. 
Many languages have so-called oblique arguments, which as a first approximation can be defined as essential participants encoded in the same way as typical adjuncts (for example, the recipients of verbs of giving in ditransitive constructions of the indirective type). Languages in which beneficiaries are encoded as objects in applicative constructions show another type of mismatch between semantic obligatoriness vs. optionality and the syntactic distinction between core terms and obliques, with a participant whose status as an adjunct is generally taken for granted taking priority over the patient of typical transitive verbs.

The observation of applicative constructions involving a patient and a beneficiary shows that the syntactic distinction between core and non-core nominal terms must be sensitive to factors other than the obligatoriness vs. optionality of participants. It is reasonable to think that the syntactic organization of applicative constructions has functional motivations, but this syntactic organization contradicts the hypothesis of a straightforward relationship between the syntactic distinction between core terms and obliques and the obligatoriness vs. optionality of participant roles.

To conclude, it would certainly be exaggerated to argue that the mismatches examined in this paper support the conclusion that the syntactic distinction between core terms and obliques has no relationship at all with the obligatoriness $v s$. optionality of participant roles. They rather support a prototype approach to semantic argumenthood that does not try to reduce the distinction between argument and adjuncts to a simple dichotomy between obligatory and optional participant roles. A finer-grained characterization of the degree of involvement of participants would be necessary in order to be able to characterize participant roles in terms of closeness to / deviation from the prototypes of argument and adjunct. What I have tried to show in this article on the example of beneficiaries is that the syntactic distinction between core terms and obliques is language-specific to a considerable extent. A notion of semantic argumenthood likely to explain the syntactic distinction between core terms and oblique must be compatible with this variation, which excludes a simplistic conception of semantic argumenthood.

\section{Abbreviations}

ABM: ablative modalis, ABS: absolutive, APPL: applicative, CAUS: causative, CL: noun class, CMP: completive, COP: copula, CVB: converb, DAT: dative, DEF: definite, DET: determiner, ERG: ergative, GEN: genitive, HPL: human plural, INCMP: incompletive, IND: indicative, N: neuter, OBL: oblique, PASS: passive, PERF: perfective, PL: plural, POS: positive, SG: singular, SUB: subject, TR: transitive. 


\section{References}

Creissels, Denis. 2004. Non-canonical applicatives and focalization in Tswana. Unpublished paper presented at the SWL1 conference (Leipzig, August 5-8, 2004), accessible at http://www.deniscreissels.fr/public/Creissels-non-canon.appl.pdf.

----- To appear (a). Valency properties of Mandinka verbs. Handbook of Valency Classes, ed. by Bernard Comrie and Andrej Malchukov.

----- To appear (b). P-lability and radical P-alignment. Typology of labile verbs: Focus on diachrony (special issue of Linguistics), ed. by Leonid Kulikov and Nikolaos Lavidas.

Grimshaw, Jane. 1990. Argument structure. Cambridge, MA: MIT Press.

Jackendoff, Ray. 1977. X-bar syntax: A study of phrase structure. Cambridge, MA: MIT Press.

Kaswanti Purwo, B. 1997. The direct object in bi-transitive clauses in Indonesian. Grammatical relations: a functionalist perspective, ed. by Talmy Givón, 233-52. Amsterdam/Philadelphia: John Benjamins.

Kittilä, Seppo and Fernando Zúñiga. 2010. Benefaction and malefaction from a cross-linguistic perspective. Benefactives and Malefactives, ed. by Fernando Zúñiga and Seppo Kittilä, 128. Amsterdam/Philadelphia: John Benjamins.

Kiyosawa, Kaoru and Donna B. Gerdts. 2010. Salish Applicatives. Leiden/Boston: Brill.

Marantz, Alec. 1984. On the nature of grammatical relations. Cambridge, MA: MIT Press.

Miyaoka, Osahito. 2012. A Grammar of Central Alaskan Yupik. Berlin: de Gruyter Mouton.

Nichols Johanna, David Peterson, and Jonathan Barnes. 2004. Transitivizing and detransitivizing languages. Linguistic Typology 8: 149-211.

Peterson, David A. 2007. Applicative constructions. Oxford University Press.

Pollard, Carl and Ivan A. Sag. 1987. An information-based syntax and semantics. Volume 1: Fundamentals. CSLI Lecture Notes, number 13. Leland Stanford Junior University: Center for the Study of Language and Information.

Schütze, Carlson T. 1995. PP attachment and argumenthood. MIT Working Papers in Linguistics 26.95-151.

Van de Velde, Mark. 2008. A grammar of Eton. Mouton de Gruyter.

Author's Contact Information:

Denis Creissels

Denis.Creissels@univ-lyon2.fr 